\title{
Chapter 4 \\ Into the Twentieth Century: The Case of Robert Oppenheimer
}

\subsection{Introduction: Daybreak and Crisis}

In 1935, philosopher Edmund Husserl argued that the European sciences (notably physics) were facing a crisis, not in terms of scientific achievements, but in terms of their meaning for culture and society, for human existence. Science had always been a moral factor, Husserl argued, had decisively contributed to the humanisation and enlightenment of human culture, to the realisation of the idea of human beings as reasonable citizens of a humane society. But now, scientific research, precisely because (in the era of quantum physics) it had become so astonishingly successful, represented a threat to civilisation. It was increasingly questionable whether human ethics and politics would be able to master the technological power unleashed by science. The ethical profile of science had become ambivalent. Science and technology had become neutral forces employable for multiple purposes, good and bad. From a benefactor of humanity and culture, science had turned into a substantial risk. Husserl also claimed that, in 1935, only a small number of individuals (true philosophers, acting as "functionaries of humanity", p. 17) were aware of the critical nature of the situation, although the broader public (Stockmann's "majority" as it were) would discover sooner or later what was at stake. In August 1945, when two nuclear bombs were dropped on Japanese cities, Husserl's gloomy predictions seemed to be confirmed. The atomic bomb became a kind of historical end-point or dead-end. As Peter Sloterdijk, in his reply to Husserl's pupil Martin Heidegger, later formulated it, the history of science is like the burning away of a conceptual fuse winding from Athens to Hiroshima. ${ }^{1}$

\footnotetext{
1 "Die Geschichte der Wahrheit ist das Abbrennen einer begrifflichen Zündschnur, die sich von Athen nach Hiroshima windet" (Sloterdijk 2001, p. 214).
} 
Husserl's message can be captured using Lacan's schematic analysis of university discourse:

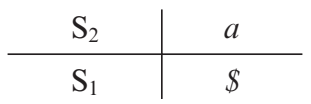

The upper level refers to the actual achievements of modern science (since the beginning of modernity): the scientific breakthroughs. But Husserl rather focusses on the forces at work beneath the bar. Rather than being neutral, Husserl argues, scientific research had always been driven (albeit tacitly) by a normative ideal $\left(S_{1}\right.$ in the lower-left position). A latent truth, a basic conviction, a moral vocation had always been at work in modern research practices. But now, during the first decades of the twentieth century, physicists ( $\mathrm{S}_{2}$ in the upper-left position, as agents) are confronted with enigmatic entities (elementary particles: $a$ in the upper-right position), which not only open-up previously unknown dimensions of reality (the subatomic realm), but also unleash unprecedented forms of power, resulting in an existential crisis, as by-product of university discourse ( $\$$ in the lower-right position).

The transition leading from quantum physics to nuclear warfare has been amply documented. In this section I will reread this history from a Lacanian perspective, focussing on the case of Robert Oppenheimer, whose life story became the subject matter of a novel (by Haakon Chevalier 1959), a play (by Heinar Kipphardt 1964) and an opera (by John Adams 2005). A strict (technocratic) definition of misconduct focusses on fabrication, falsification and plagiarism of data (FFP), as we have seen, so that questions such as whether it is condonable for scientists to contribute to the development of a genocidal bomb (explicitly developed for massive destruction of urban areas) falls outside the scope of the integrity discourse sensu stricto. But the case of Robert Oppenheimer cannot be ignored for various reasons, ranging from questions concerning sensitive data management (the physicist as a "security risk") up to the function of the death drive, of which his atomic bomb seems the very embodiment. But the death drive also functions on the micro-scale, as a suicidal component (a tendency towards intellectual "suicide") discernible in many cases of misconduct, even in the FFP sense of the term. Starting point for the analysis is The American Prometheus, the 719-page Oppenheimer biography written by Kai Bird and Martin Sherwin (2005/2006).

\subsection{American Prometheus: A Science Biography Classic}

Oppenheimer was born in New York in 1904, but studied in Europe, where he became a "second wave" quantum physicist, following in the footsteps of "quantum giants" of the first generation such as Bohr, Heisenberg, Schrödinger, Pauli and Dirac (Bird and Sherwin 2005/2006, p. 78). Eventually, he achieved iconic status as the most famous scientist of his era, due to his leading role in the Manhattan project, 
which resulted in the production and testing of the first atomic bomb (known among initiates as the gadget), in Los Alamos, New Mexico: an event which profoundly transformed global politics. After the War, he became Director of the prestigious Institute for Advanced Study at Princeton, but he was formally declared a security risk in 1954, due to his connections with communism and the Communist Party in the 1930s and 1940s. Before his appointment as Director of the Manhattan Project, Oppenheimer had been an active member of numerous Communist front organizations and had been closely associated with Communist Party members, including his wife Kitty and his brother Frank.

Thousands of pages of FBI records concerning the Oppenheimer case were accumulated over decades of surveillance, while the transcripts of his security hearing by the United States Atomic Energy Commission (AEC) in 1954 (resulting in his security clearance being revoked), published as In the Matter of J. Robert Oppenheimer, consisted of 3000 typewritten pages, comprising some 750,000 words, 993 densely printed pages (p. 546): a stack of papers $4 \mathrm{ft}$ high (p. 545). Rather than on his role in the actual production of the atomic bomb, however, these inquiries focussed on the question whether Oppenheimer was co-responsible for leaking nuclear information to the Soviet Union. His integrity was questioned and he was accused of "fabrication" (p. 508), albeit not of research data. Rather, these accusations revolved around a "fabricated" story meant to cover up a conversation with Communist Party member Haakon Chevalier about funnelling classified information to the Soviet Consulate in San Francisco in 1943 (p. 509). Chevalier would eventually publish his own version of the Oppenheimer case, in the form of an autobiographical account of their friendship (1965), but also in the form of a romanà-clef (Chevalier 1959): a story about an intelligence officer who, under the cover of an academic position, is actually employed by the U.S. secret service to report on Robert Oppenheimer (who appears in the novel under the pseudonym of Sebastian Bloch).

The question "Who was Robert Oppenheimer" is difficult to answer, as he was generally regarded an "enigma" (Bird and Sherwin 2005/2006, p. 5; cf. Bernstein 2004). Outwardly speaking, Oppenheimer was a chain smoker with a remarkably frail and delicate physical appearance (weighing something like 115 pounds). As a scientist, he was regarded a "verbal" and "imaginative" physicist. He was considered a "weak", "clumsy" or even "inept" experimentalist whose mathematics was regarded as "deficient", but Oppenheimer displayed a rare talent for grasping and combining new and challenging conceptual ideas. ${ }^{2}$ As soon as Otto Hahn and Fritz Strassmann had demonstrated that the uranium nucleus could be split for instance (on January 29, 1939), Oppenheimer began to speculate that uranium could be used to make bombs (p. 166). Before long, there appeared a drawing of an atomic bomb

\footnotetext{
${ }^{2}$ Although Oppenheimer is generally regarded as one of the leading theoretical physicists of his generation, and authored and co-authored important papers on issues ranging from the positron up to black holes, he has not been credited with any "discoveries", which is attributed to his "philosophical attitude": his quest for more profound and basic insights than theoretical physics offered (Pais et al. 1969).
} 
on the blackboard in Oppenheimer's office, based on the idea of a nuclear chain reaction (p. 168). But he was also famous for his language gift. Besides his mastery of modern languages such as German, French, Italian and Dutch, he read the Hindu classic Bhagavad-Gita in Sanskrit. He also was an avid reader of poetry (Dante, Donne, Baudelaire and Eliot among others). As Director of the Institute for Advanced Study, he invited the poet T.S. Eliot to Princeton in 1948, where, besides writing The Cocktail Party, he was supposed to interact with exact scientists such as Gödel, Einstein and Von Neumann.

Last but not least, much like his supervisor Wolfgang Pauli, Oppenheimer was "intensely interested" (p. 126) in psychoanalysis. Pauli even joked that psychoanalysis was Oppenheimer's true "vocation", while physics was merely his "avocation" (p. 78). Already in 1925, after he had left a cyanide-poisoned apple on the desk of a lab colleague while suffering from symptoms such as insomnia, nervous tics, ceaseless smoking and "incessant talking", his mother insisted that he saw a French psychoanalyst in Paris (p. 47). But rather than subjecting himself to analytical sessions, he became "his own psychoanalyst" (p. 48). At Berkeley he studied psychoanalysis intensely, and joined a trans-disciplinary study group led by Siegfried Bernfeld, a disciple of Sigmund Freud who had settled in San Francisco in 1937, where he tried to integrate psychoanalysis with Marxism, meanwhile acting as training analyst of Jean Tatlock, a Jungian communist with whom Oppenheimer had an extramarital affair until she committed suicide.

In 1942, Oppenheimer was appointed by General Leslie Groves to lead the secret weapon laboratory of the Manhattan Project. Oppenheimer's appointment came as a surprise. He had no experience in directing large groups and, as a theoretical physicist, hardly knew anything about equipment, while the Manhattan Project was decidedly a technological project. Moreover, many of Oppenheimer's closest associates were or had been Communist Party members in the 1930s or 1940s, including his brother Frank, his wife Kitty, his mistress Jean Tatlock and several of his graduate students at Berkeley. But Groves relied on Oppenheimer, who somehow was able to transform himself "from an awkward scientific prodigy into a sophisticated and charismatic manager" (p. 179). This implied that he had to "conjure up skills he did not yet have, deal with problems he had never imagined, develop habits that were entirely at odds with his previous lifestyle and adjust to modes of behaviour that were alien to his experience" (p. 205). Indeed, Robert Oppenheimer had to remake a significant part of his personality. From a small-scale theorist he "metamorphosed into a charismatic, efficient administrator", running a project the logistics of which were "horrendously complicated" (p. 209). The eccentric theoretical physicist became a highly organised leader (cf. Thorpe and Shapin 2000). In a few months, he apparently corrected his naivety and communicative deficiencies and proved able to direct an industrial-scale enterprise.

In his capacity as research director, Oppenheimer oversaw the production of "the gadget", a metal globe containing uranium and studded with detonator plugs. Oppenheimer personally selected the location where the gadget was to be tested, naming the site Trinity, in reference to the metaphysical poet John Donne, but also to the Hindu deities Brahma (the creator), Vishnu (the preserver) and Shiva (the 
destroyer). When (on July 16, 1945, at 5:29 a.m.) the gadget finally exploded, the horizon lit up with a tremendous flash, changing into a big orange ball, while night turned into day. At that moment, Oppenheimer's face allegedly relaxed into an expression of tremendous relief, after which he quoted a famous line from the Bhagavad-Gita: "Now I am become death, the destroyer of worlds" (p. 309).

As a university professor in theoretical physics, Robert Oppenheimer's position initially represented what Lacan refers to as university discourse:

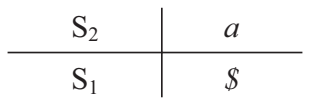

Oppenheimer was a physics researcher who later became a research manager and an atomic expert ( $S_{2}$ in the upper-left position as agent). At Berkeley, Oppenheimer was not only committed to research, however, but he was also an active participant in communist circles. He shared his fascination for and even involvement in communism with many contemporary scientists active in his field, including Linus Pauling, David Bohm and Maurice Wilkins (Zwart 2015d). As was already explained above, Lacan regarded the Soviet Union as a science-based society, under the sway of university discourse, a society designed and led by political engineers. And the nuclear research facility at Los Alamos (the site of the Manhattan project) was basically a scientific kolkhoz, an exemplification of scientific collectivisation. In the 1930s and 1940s, communism was a political ideology which decidedly appealed to scientists (notably physicists). It was university discourse elevated to the level of world politics.

As a research manager, Oppenheimer $\left(\mathrm{S}_{2}\right)$ focussed his attention on the "gadget": the primordial, prototypical atomic bomb, the Manhattan Project's object $a$ (in the upper-right position). But precisely as object $a$, the gadget played an elusive and recalcitrant role. During the construction process, the gadget seemed something tangible and physical, but it remained uncertain whether it would work, whether the contraption they were building really was a gadget (i.e. a prototype atomic bomb). It was uncertain what exactly it would do. It remained highly unclear whether the gadget would really unleash a nuclear chain reaction. But as soon as the experiment succeeded, the gadget (as a physical object) was obliterated, not only because, after the explosion, all that remained was an empty, contaminated spot in the desert, but also because, as soon as the gadget exploded, it became a completely different kind of entity, namely a political object, which was therefore immediately taken out of the hands of the physicists. As soon as the gadget actually worked, it was subjected to compartmentalisation. Before the explosion, the gadget had been a scientific entity, a contraption in the hands of the scientists, but after the explosion, it became a weapon of mass destruction, and fell into the hands of the military. In other words, the ontological status of the gadget (questionable from the very start) drastically changed. As soon as the gadget (the object $a$ ) really proved to be the first atomic bomb, the scientists were barred from access to this bomb; they were left empty handed as it were: they were expropriated. Indeed, from now on, the scientific sub- 
ject, the nuclear physics expert, became a security risk, a potential leak of classified information. Scientists who worked for the Manhattan Project had no say whatsoever concerning the actual use of the bomb. Like other citizens, they were informed about the bombing of Hiroshima and Nagasaki via the newspapers, via the mass media (Wilkins 2003). They had no say in the matter at all. After the explosion, after the birth trauma, the birth of the bomb, the umbilical cord which had connected them with the bomb was immediately severed.

The gadget, the object $a$, proved a toxic entity moreover, disrupting the scientific subject, putting many of the scientists involved out of balance in various ways. Some physicist involved in the Manhattan project (Klaus Fuchs for instance) saw the gadget as a threat to world peace and decided to become spies, even if this meant deflecting to the Soviet Union, while others (Maurice Wilkins, for instance) left the field of physics research, in order to migrate into other emerging research arenas, such as the molecular life sciences (deflecting from the science of death towards the science of life, as Wilkins himself formulated it). And even Wilkins (who later contributed to the discovery of the structure of DNA in 1953) was suspected of espionage (Zwart 2015d). Thus, while Oppenheimer and Groves had been working closely together to make the Manhattan Project a success, after the explosion a rupture between science and politics was enforced. The military use of the bomb would be controlled "exclusively by the White House, with no input from the scientists who over the past two years had been building the bomb" (p. 293). After Trinity, "the gadget had become a weapon, and weapons were controlled by the military" (p. 313). Scientists had "no proprietary rights" (p. 300) over the bomb and were sent back to their universities and laboratories (p. 294).

This eventually even applied to Oppenheimer himself. His frantic post-war efforts to influence global nuclear policy dramatically failed. After the revoking of his security clearance, President Eisenhower himself decided that "a complete bar" was to be erected "between this individual [Oppenheimer] and any information of a sensitive or classified character" (p. 480). He issued a formal note ordering to place "a blank wall" between Oppenheimer and classified material (p. 480). Thus the "object $a$ " of nuclear physics experienced what in metaphysics is known as transubstantiation (Aquinas 1922, Pars III, Q. 75, Art. 4): whereas in material terms the entity (the atomic bomb) may appear to be the same, its ontological status, it noumenal essence has dramatically changed. A research project produced a gadget which, via self-obliteration, transubstantiated into a bomb, or rather: into the bomb, so that the object $a$ (the object of the will to know) became the A-bomb, as exemplified by the following two pictures: 


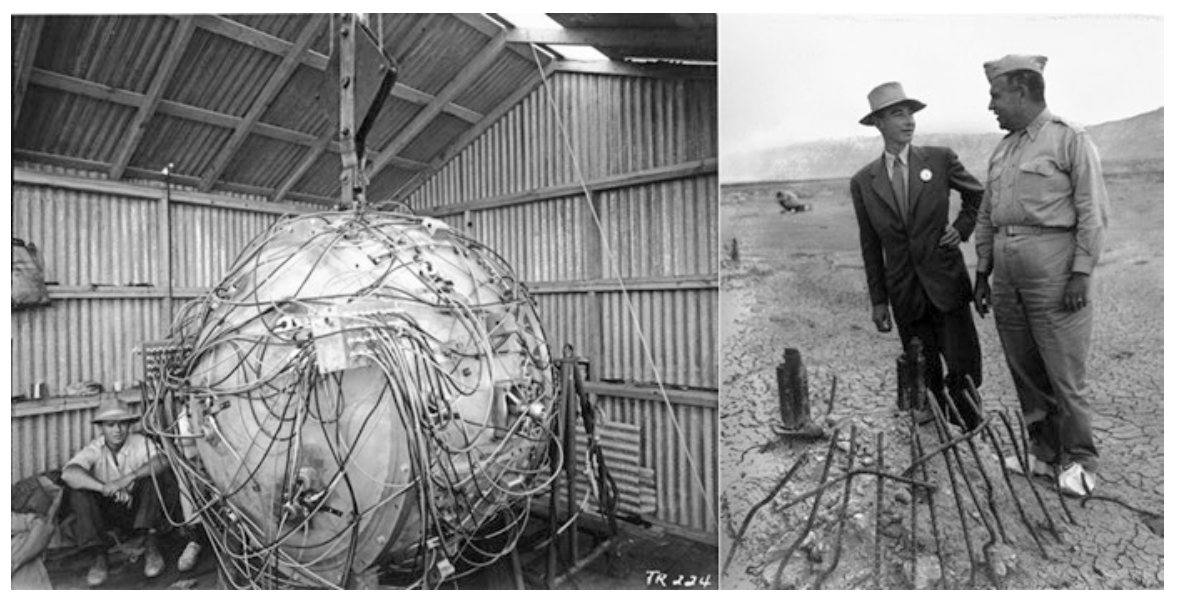

In the picture on the left, the gadget is physically present, but as an intriguing research object. The picture on the right shows Oppenheimer and Groves right after the explosion. The gadget is now absent, has obliterated itself, and yet, it is only now that it has come into existence, that it is more existent than ever. Through its sudden physical disappearance, its dissolution, it has become the most terrible weapon of destruction ever built: an "awful thing" (p. 301), a symbolic entity which transformed the United States into the world's first nuclear power. "We have made a thing", Oppenheimer told the American Philosophical Society, "an evil thing" that has "altered abruptly and profoundly the nature of the world" (p. 323).

But the explosion not only resulted in transubstantiation at the object-pole, it also dramatically affected the subject-pole. Many physicists working on the project were troubled by ethical qualms about their genocidal bomb. Ethical deliberations emerged as a by-product of the project ( $\$$ in the lower-right position). At a certain point for instance, a meeting was organised in Los Alamos to discuss "the impact of the gadget on civilisation". Unsettling doubts concerning the moral legitimacy of the whole endeavour ( $\$$ in the lower-right position) aggravated after Germany surrendered. And after the War, the bomb provoked an exodus of physicists into other fields such as biology, resulting in the birth of the molecular life sciences, as a transdisciplinary research field, paving the way for the human genome project (funded by the U.S. Department of Energy because of this organisation's interest in the genetic damage inflicted by nuclear warfare).

This dynamics can be elucidated with the help of Lacan's quadruped. Initially, Oppenheimer is a scientist $\left(\mathrm{S}_{2}\right)$ working on a project which revolves around a particular object: the gadget $(a)$, and its core component: the Uranium isotope 235 (Uranium-235), an unstable, "fissile" isotope, usable for igniting an unsettling scenario: a nuclear chain reaction ( $a$ in the upper-right position). It is not at all a "normal", domesticated object, but rather an entity which destabilises and dramatically affects its environment, not only on the macro-level (in terms of the organisations and institutions involved in the research, for the Manhattan Project gave rise to big 
science and the militarisation of research), but also on the micro-level (the ethical qualms of the individual scientists who managed to bring this entity into existence). After the explosion the doubts and concerns of individuals (as divided subjects) aggravated, transforming them into security risks. Leaking classified information became a singular form of "misconduct", closely connected with the bomb project. Whereas normal science depends on the free exchange of information, certain forms of information were suddenly labelled as highly confidential. In a dramatically changed political landscape, the physicists experienced a split (Spaltung) between their scientific vocation and their political obligations. In other words, the splitting of the atom (a) corresponded with a splitting of the scientific subject $\left(\mathrm{S}_{2} \rightarrow \$\right)$. Oppenheimer was not a purely detached, objective, impassive, replaceable, etc. researcher, but rather fuelled by a basic truth, which surfaced on July 16, 1945, when, by citing his Hindu quote, he articulated, in a very condensed way, his spiritual understanding of the eternal cycle of creation, preservation and destruction $\left(\mathrm{S}_{1}\right.$ in the lower-left position).

The subsequent appropriation of the atomic bomb by the State (depriving the collectivised scientific workers, who had been put to work at the Los Alamos kolkhoz, of their surplus value, their object $a$ ) resulted, in Lacanian terms, in a temporary resurgence of the discourse of the Master. By taking possession of the bomb, in order to ascertain a position of nuclear monopoly, the U.S. President basically claimed "World order, c'est moi" ( $\mathrm{S}_{1}$ now in the upper-left position as agent). The world from now on revolved around the bomb and the position of the U.S. President was from now on defined by and closely associated with the bomb. During the Truman Administration, sensitivity to ethical qualms concerning the legitimacy of the development and use of genocidal weapons $(\$)$ was pushed beneath the bar $(\$$ now in the lower-left position), as the U.S. presidency aimed to use its nuclear monopoly to establish global political supremacy, a position of power relying on the bomb, pushing scientists back into the position of scientific workers: recipients of instructions from those in power ( $S_{2}$ in the upper-right position), in accordance with the dynamics of the Master's discourse:

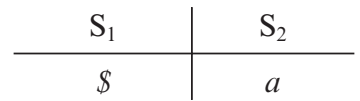

This resulted in what Karl Marx (1867/1979) referred to as expropriation or estrangement. The physicists were confronted with the product of their own labour (the bombs dropped on Hiroshima and Nagasaki: $a$ in the lower-right position) indirectly, via the newspapers, while politicians consolidated their power position by expropriating this product of research (this by-product of the quantum physics revolution). The physicists lost control over their gadget. The object of their cupido sciendi was appropriated by the State and transubstantiated into a political entity: the most decisive by-product of the war effort ( $a$ in the lower-right position), destined to transform the global political landscape, the global symbolical order. From now on, "scientists could serve the state only as experts on narrow scientific issues" (p. 549). 
The discursive landscape took a quarter-turn to the right, temporarily restoring a form of Master's discourse, of absolutism, providing the U.S. with absolute power, albeit temporarily, for this political coup d'état soon proved anachronistic and unstable. For de facto the new power regime continued to rely quite heavily on scientific and administrative expertise, so that the power of expert knowledge continued to hold sway. As soon as the object $a$ proliferated to other states, notably the Soviet Union (as the very embodiment of social engineering and university discourse), absolutism (the Master's discourse) dissipated once again, and power fell into the hands of a new type of experts ( $S_{2}$ again in the position of agent), namely professional administrators and nuclear diplomacy experts, of the Henri Kissinger type: a nuclear strategist informed by game theory and behavioural research (p. 559) who, in the 1950s, served as consultant for the Psychological Strategy Board, set up in support of the transition from traditional warfare to what came to be known as "psychological warfare" (Osgood 2002).

Oppenheimer's own strategy during the aftermath of World War II was basically a frantic effort to maintain his position of influence (as a physicist) within this changing global landscape. Physicists, he argued, should have a say in the transnational management of the bomb. An international atomic authority was to be established, placing the bomb under international control, so that all countries, including the Unites States, should voluntarily agree to a "partial renunciation of sovereignty" (Bird and Sherwin 2005/2006, p. 342). To this global supra-national authority (an exemplification of politics under the sway of university discourse, steered by scientists), countries should relegate ownership of uranium mines, atomic power plants and nuclear physics laboratories. But this vision, this strategy, this fantasy perhaps, dramatically faltered. Instead, the political reliability of physicists, including Oppenheimer himself, was increasingly seen as questionable. Soon, the role of nuclear physics experts was taken over by arms race experts and professional administrators of the atomic era (now representing $S_{2}$ in the upper-left position). Rather than playing the role of absolute monarch, the American President and other world leaders again came to rely on export knowledge (in accordance with the logic of university discourse), represented by political scientists (such as Kissinger) rather than physicists, who were again regarded as mere human resources, as the brain power of high capitalism.

This reign of university discourse (with experts like Kissinger replacing intellectuals like Oppenheimer) would soon be confronted with another quarter-turn to the right, however, giving rise to the discourse of the hysteric, placing $\$$ in the upper-left position of the agent, challenging and questioning the position of those who were placed in responsible positions $\left(S_{1}\right.$ in the upper-right position). The discourse of the hysteric was represented by the anti-war and disarmament movement of the 1960s and 1970s:

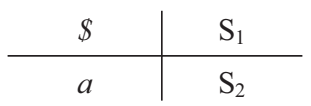


But this constellation (this collision between university discourse and the discourse of the hysteric, between $S_{2}$ and $\$$ as agent) eventually reinforced the position of the nuclear technocrat, the policy expert (in accordance with the logic of university discourse). Protests against the bomb produced a new type of expertise, specialised in the development and governance of more "humane" and sophisticated forms of nuclear warfare $\left(S_{2}\right.$ in the lower-right position, as by-product of anti-nuclear protest). ${ }^{3}$ Meanwhile, Oppenheimer himself, so politically engaged in the 1930s and 1940s, was "oddly disconnected from the political turmoil (the cold war and antiwar 'hysterics') of the 1960s" (p. 578). At the beginning of the decade, as many Americans dug atomic bomb shelters in their backyards, Oppenheimer "never spoke out against such hysteria... Similarly, as the Vietnam War escalated in 1965-66, he had nothing to say in public" (p. 578).

From the perspective of the discourse of the hysteric, Oppenheimer's position of silence and withdrawal may seem awkward and disappointing, but his position as a withdrawn sage during the final years of his life becomes understandable if we revert to the discourse of the analyst (quarter turn to the right):

\begin{tabular}{c|c}
$a$ & $\$$ \\
\hline $\mathrm{S}_{2}$ & $\mathrm{~S}_{1}$
\end{tabular}

During the final years of his life, Oppenheimer was primarily engaged in selfreflection, a process of analysis and catharsis revolving around the gadget, the object $a$, as the thing which set his life in motion, which had addressed him, which had both stabilised him (helping him to overcome the neurotic, solipsistic egocentricity of his youth, transforming him into a charismatic leader) and destabilised him (leading to his fall from grace in 1954). The gadget allowed him to develop an identity, to make a name for himself, the object $a$ defined his life, but it also ruined him in the end. On the macro-level the gadget transformed (destabilised and subsequently stabilised) world politics. From the perspective of the analyst, the gadget, the "object $a$ " is the agent, determining history, making and breaking scientific careers ( $a$ in the upper-left position as agent), with physicists as the ones who were the first in line to be addressed by this gadget: $\$$ in the upper-right position. During the final stage of his life, Oppenheimer hardly functioned as a physicist, in the scientific sense of the term, his expertise was suspended ( $\mathrm{S}_{2}$ now pushed into the lower-left position). One could argue that, rather than a scientist, he became a kind of sage: silent, withdrawn and enigmatic, a "modern seer, a thoughtful, enigmatic philosopher of the role of science in the modern world" (p. 560). In other words: $S_{1}$ in the lower-right position (wisdom as ultimate by-product of biographical drama). In the next sections, I will

\footnotetext{
${ }^{3}$ This development is comparable to how the boom of hysterical discourse in academic quarters in the late 1960s and 1970s (May '68 and so on) gave rise (paradoxically perhaps) to the current regime of technocrats and managers, of performance indicators and performativity scores that currently dominate most Western universities ( $\mathrm{S}_{2}$ as a by-product of 'hysterical' protest). As Lacan (1969-1970/1991) predicted, the discourse of the hysteric emphatically addresses the Master (as recipient of the message, $S_{1}$ in the upper-right position) but inevitably reinforces the power of the technocrats (as by-product, $\mathrm{S}_{2}$ in the lower-right position).
} 
explore these discursive turns in more detail, analysing this case history from an oblique perspective, focussing on The Man who would be God, a science novel about Oppenheimer written by Haakon Chevalier (1959).

\subsection{Oppenheimer in Fiction: The Man Who Would Be God}

The case of Robert Oppenheimer is a prominent case study for science ethics, but also a source of inspiration for genres of the imagination. I already mentioned the German playwright Heinar Kipphardt who devoted a play to Oppenheimer, written in the vein of Bertolt Brecht's Leben des Galilei and focussing on the hearings to which Oppenheimer was subjected in 1954. In fact, the title (In der Sache J. Robert Oppenheimer) is the literal translation of the published version of the transcript of the procedures. More recently, in 2005, American composer John Adams devoted a remarkable Opera to the case, entitled Doctor Atomic.

The following sections focus on a novel devoted to the Oppenheimer case, written by Haakon Chevalier who, besides being a translator and assistant professor of French Literature at Berkeley, was also a member of the Communist Party and a close friend of the Oppenheimers during their Berkeley episode. The novel (written in San Francisco in 1948 and finished in Paris in 1958) is actually a roman à clef. Oppenheimer, the key protagonist, is easily recognisable under the pseudonym Sebastian Bloch, and his wife Kitty (Tanya Bloch) is portrayed quite recognisably as well. Although Chevalier served as a translator during the Nuremberg trials and translated various books, notably by surrealist writers such as Louis Aragon and Salvador Dali, he is most famous for his role in the so-called Chevalier Incident that dominated the Oppenheimer hearings. In February 1943, the two friends had a brief conversation in Oppenheimer's kitchen (where Robert was preparing martinis) concerning a proposal from George Eltenton, a communist scientist educated at Cambridge and employed by the Shell Oil Company (Bird and Sherwin 2005/2006, p. 195). Exactly what was said became the subject of much controversy during the 1954 hearings, but according to Chevalier, Eltenton had solicited him to ask his friend Oppenheimer to pass on information about the Manhattan Project to a diplomat in the Soviet consulate in San Francisco, who would probably want to funnel the information to the Soviet Union. Oppenheimer rejected the overture, but later became entangled in contradictory accounts of what had actually been said. Oppenheimer apparently declined to have anything to do with the proposal and Chevalier later insisted that he was only alerting his friend to it, rather than acting as a conduit. Although Oppenheimer was director at Los Alamos at that time, he never reported the event (which he should have done), and during the hearings Oppenheimer's integrity was therefore questioned. Notably, Oppenheimer was forced to confess to having produced multiple inconsistent versions of the event. As the Chevalier novel phrases it, he was accused of "fabrication" (1957, p. 508). In the novel version, the Chevalier incident is set in Bloch's garden (instead of the kitchen), involving German physicists rather than Soviet agents, but the incident plays a similar role in the novel as in real life. 
The main protagonist of the novel, however, is Mark Ampter, who actually resembles Haakon Chevalier in various respects. Ampter works at Berkeley University, becomes an active member of a Marxist unit (of which Sebastian is the most inspirational member), joins the Berkeley branch of the teachers' union (a communist front organisation) and becomes involved in various other leftist causes, - all this closely corresponds with Chevalier's own biography. Moreover, Mark Ampter and his wife Eve (Barbara Chevalier) become close friends of the Bloch couple. And finally, in Chevalier's novel, there is a crucial scene about miscommunication: the garden scene, the turning point in the novel, uncannily reminiscent of the Chevalier Incident. When Mark seems finally able to pass a secret message (allegedly coming from German scientists) which he was requested to communicate to Bloch, the latter suggests to step out into the garden, away from hidden microphones (knowing that otherwise the conversation would be taped). Oppenheimer (Bloch) was fully aware of being under more or less constant observation. Virtually everything he said was being monitored. Unfortunately, their conversation (meant to straighten things out) was interrupted (in real life Kitty was impatiently waiting for the arrival of the martinis, and in the novel Tanya urged Sebastian to come and entertain his guests), never to be taken up again.

Another remarkable similarity between Mark Ampter and Haakon Chevalier is that for both, the university job was basically a cover. Chevalier used it for his communist activism, Ampter for reporting on Bloch, which also highlights the most remarkable difference between both men. For instead of being a communist, Mark Ampter is actually working as a secret agent. His assignment is to infiltrate the radical left-wing milieu of scientists at Berkeley in order to observe "the mechanism of subversion, disruption and sabotage" from the inside (p. 88). His first and foremost objective, however, is to report on Sebastian Bloch. Berkeley campus is basically a breeding ground for subversive activities (both according to the Communist Party and according to the Secret Service) and Bloch is regarded as one of the key actors hunting for converts, thus spreading the infection. His influence is "poison", as Gospodin Gregg (Ampter's chief) phrases it (p. 165). In the context of his assignment, Mark Ampter produces an enormous pile of reports concerning Bloch and his entourage (comparable to the 3000 typewritten pages produced by the FBI used as evidence during the Oppenheimer hearings). In other words, Chevalier and Ampter represent opposite extremes of the political spectrum: Chevalier as a member of the Communist Party (receiving instructions from Moscow), Ampter as an employee of the (anti-communist) secret service (operating from Washington). Chevalier himself figured high on the watch-list of secret intelligence agencies as a possible Soviet spy. But although being political opposites, the Communist party and the secret service are both organisations that are shrouded in secrecy and actually mirror one another. Communists are monitored and at times harassed, not only by the secret service, but also by their own organisation. In the novel, both organisations devote much of their time and resources to enrolling (and monitoring) new recruits, infiltrating various movements to achieve this. Both the secret service and the communist party are organisations of the Big Brother-type: taking over people's lives while collecting potentially damaging information about individual members for possible 
future use. Moreover, recruitment (either into the Communist Party or into the Secret Service) results in "compartmentalisation" (p. 208), in a split existence, a double life. The official profession of the person involved becomes a cover-up for carrying out secret assignments, about which only inner circle party members and/ or the secret service are informed. Chevalier's novel describes how three organisations, namely the university, the Communist Party and the Secret Service, become intimately entangled with one another.

But things become even more complicated when Mark Ampter not only feels quite at home in "enemy territory", but increasingly starts to fall under the influence of Bloch. He is "overwhelmed by Bloch's personality", by his charisma, his "towering intellect" (p. 67). It is as if the latter is "casting a curious spell over him" (p. 57), as if Mark has lived all his life in a kind of vacuum and now suddenly discovers "reality" (p. 59). He strongly "identifies" with Bloch (p. 59), even "imitates his mannerisms" (p. 95). For him, Bloch embodies an ideal. He is the type of person who fulfils the requirements of leadership spelled out by Freud in his psychology of the masses (1921/1940): endowed with sufficient charisma and prestige so that junior group members can identify themselves with him (up to the point of copying phrases and mimicking gestures). Ampter decides to try to leave the secret service and to join the leftist movement, in other words he opts for apostasy, going native, moving over to the enemy camp to become "a free citizen" once more, with a "respectable profession" (p. 189). But he soon realises that cleansing himself of his past is not as easy as it seems. Although in retrospect he regards the entire investigation of Bloch a mistake, his work for the secret service cannot be "blotted out" (p. 318), not even by joining the army, where he becoming seriously injured in battle. Even worse, his superior (Gregg, nicknamed the Chief) refuses to regard the detailed reports on Bloch which he produced (the "mass of derogatory information against Bloch", p. 441) as "fabrications" (p. 195). The damaging information he had been collecting on his new friends and colleagues already found its way into the files, their files (p. 183). ${ }^{4}$ His integrity cannot be restored, so that Mark will remain marked (as an informant) for life.

The novel revolves around the bomb, referred to as the Thing, the gadget, the Bolt, the contraption, etc. It is described almost as a living organism, an "embryo" at first (p. 217). In the course of its growth process, it changes the power field dramatically. At first there is only an abstract concept, without a body, without reality: calculations on a blackboard. Step by step, however, the "Thing" becomes increasingly real. Bloch's appointment as director of the research facilities at Los Alamos (surnamed Valhalla in the novel) forces him to break all ties with his leftwing past. His involvement with the Thing forces him to transform his very identity. In order to secure access to the Thing, to the bomb project, he must obtain security clearance, and initially this seems utterly impossible. This obstacle (his left-wing sympathies), which threatens to bar his access to the bomb, becomes a basic motif

\footnotetext{
4 "That wouldn't simply vanish as a result of the fact that he was quitting the security service. It was still in the record, filed away safely in the office for future reference, ready to do its damage" (p 183).
} 
in the novel: "the clearance of Dr. Sebastian Bloch" (p. 235). In order to pass security clearance, Sebastian is not only forced to abjure his political beliefs, but also to denounce his former friends, including Mark Ampter. In other words, whereas Bloch is initially a beacon of integrity, his practices become increasingly questionable, from a moral point of view, precisely because he increasingly experiences himself as desperate and vulnerable. He cannot live without the Thing and therefore he cannot afford "any suspicion of a taint of communism" (p. 204). The records concerning his un-American activities (collated in a detailed way by Ampter) make it possible (in principle) to discharge him immediately from the project, should his superiors decide to do so. Therefore, he feels completely "powerless" (p. 229). His questionable "integrity" (p. 292) as a former communist becomes his fatal weakness, especially when the intelligence service discovers that there is a "security leak" somewhere: that someone central to the project is transmitting vital material which is reaching the Soviet Union (p. 292). Sebastian seems to know something about it, seems to be withholding "some vital piece of information". When interviewed by secret service agents, he lacks the power to protect his "personal dignity" (p. 227). He realises that, in order to safeguard his addictive proximity to the bomb, he must be cooperative "to the last ignominious syllable" (p. 228), until his integrity is completely abolished and the "depth of indignity" is reached (p. 229). He suffers the "humiliation" (p. 232) of being forced to "violate his code of honour" (idem) and to betray "some of his closest comrades" (idem). His attachment to the Thing makes him a "prisoner" (p. 218). He is under constant observation (p. 221), "mistrusted, watched and followed" (p. 329). He is forced to give away "something that he would later discover it was disastrous not to have kept" (p. 308). Yet, being completely wrapped up by the Thing, being devoured by it (p. 344), he simply cannot accept to become separated from his gadget:

Deep down, he rejected the whole venture: his conscience, his spirit, the effectively human part of him, condemned it... but if the project was going ahead, then he must be in on it. The Monster must not be made without him. Such an eventuality was unthinkable (p. 217).

He dedicates "his whole being to the making of the Bolt". There can be "no conflicting allegiance or responsibility", he "commits his whole destiny" to it (p. 220). As indicated, the Thing is portrayed as a quasi-living being. ${ }^{5}$ For being allowed to interact with the Monster ( $a$ in the upper-right position) and to prevent being disconnected from the one thing on which his whole existence has come to depend, Bloch proves willing to "pay the price" (p. 282): his integrity crisis as by-product (lowerright position), in accordance with the dynamics of university discourse:

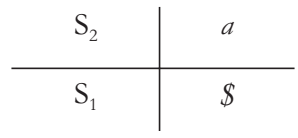

\footnotetext{
5 "The embryo of the Thing, as many referred to it, was now in full growth. To feed it, mountains of ore were being extracted from the bowels of the earth, purified in plants, where the product was sent on to undergo a succession of processings [in] scores of factories and laboratories" (p. 271).
} 
Initially, Bloch is a high-trained physicists who becomes recruited as a nuclear physics expert $\left(\mathrm{S}_{2}\right.$ in the upper-left position) to investigate how U-235 can (the object $a$ ) can be used to unleash a nuclear chain reaction. But before long, this object $a$ (the gadget, the contraption) becomes an obsession. During the years of the Bolt, Sebastian had to "rule out everything that was tangential to his overriding task" (p. 332). As a result, he becomes a divided subject ( $\$$ in the lower-right position), divided between his former loyalties and his present obsession, so that he falls victim to the matheme of desire $(\$ \diamond a)$. Bloch is now obsessed with his gadget, and Valhalla is basically machinery which allows this impossible object $a$ to come into existence, providing Bloch the privilege of access and interaction. In the next section, the vicissitudes of university discourse will be analysed in more detail.

\subsection{University Discourse: Vicissitudes and Discontents}

From a Lacanian perspective, the novel analyses (various instances) of university discourse. Remember that university discourse starts off (at the upper side of the bar) with a devoted, objective, epistemologically reformed subject $\left(\mathrm{S}_{2}\right)$ who is facing (interacting with) a purified yet elusive object $(a)$, in this case: isolated, purified Uranium. Gradually, however, it becomes apparent that this allegedly "pure" subject-object-interaction is actually challenged (haunted, contaminated) by forces coming from elsewhere (from "beneath" the bar). Not only because a Master voice is spurring the process as a voice of conscience (Thou shalt produce the bomb: $\mathrm{S}_{1}$ in the lower-left position), but also because the various frustrations, sacrifices and contradictions which emerge in the course of the process result in a tormented subject, an integrity crisis, as an unintended by-product of research $(\$$ in the lower-right position):

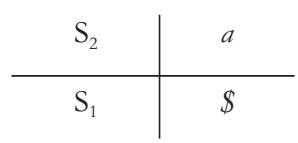

The first instance of university discourse presented in the novel is quantum physics, an allegedly pure research field. Tanya, an outsider, describes how, from her perspective, Sebastian (the archetypal physicist) belongs "to some more exalted sphere, accessible only to a very few" (p. 13), a world that is "alien to her" (p. 13), because it is "the most abstruse of scientific fields" (p. 18). In this decidedly other world (the realm of basic science), a dimension of being is studied that is completely other and alien: the world inside the atom, where strange and incomprehensible subatomic entities somehow exist and move about, although it is far from clear what existence and movement means here. Quantum physicists seem to be the most disinterested scientists of all. Quantum physics is depicted as the nec plus ultra of pure science. 
Sebastian evokes in Tanya the image of a white "swan" (p. 12, p. 24, p. 255, p. 432). She experiences him as a Lohengrin-like figure, descending from a higher realm, a vulnerable man, moreover, "made of a finer clay than the other men she had known" (p. 12), someone who "had to be protected", a fragile Knight wholly devoted to serving the Holy Grail of quantum physics: a spectral, empty, almost immaterial something, the object $a$ of quantum science (the atom and its elementary components). To her, Sebastian is "a fabulous being endowed with strange powers", absent and uncommunicative, a stranger, a mysterious persona, often away on mysterious errands, belonging to a "different order", radiating a kind of "spirituality" (p. 40). Light seems to radiate from his presence, exerting a charm that few can resist. He seems "touched with saintliness" (p. 40). An inexplicable calling $\left(S_{1}\right.$ in the lower-left position) is spurring him on. And therefore, her efforts to restore this wild swan "to his human shape" are bound to falter (p. 256).

New developments in this highly specialised field are absorbing him more and more. One day, on a blackboard, he fleshes out how a mysterious, minuscule atom may in principle unleash a nuclear chain reaction, so that something unbelievably small (an atom) may transmute into something astonishingly big: an atomic bomb. His mathematical equations reflect the Real, "mathematisation alone reaches the Real", as Lacan (1972-1973/1975, p. 165) phrases it: the unimaginable atomic world, bypassing worldviews, visual representations and written discourse. The equation predicts that the atom (the intangible, elusive object $a$ of quantum physics) is destined to become the A-bomb. The fission reaction represents pure, elementary fire (a) which $\mathrm{S}_{2}$ desperately aims to integrate, domesticate and appropriate into university discourse. It is clear to Sebastian that he, of all people, is destined to make this bomb, although the gadget will drastically remake and transform him as well.

Bloch/Oppenheimer entered quantum physics as an already established field $\left(\mathrm{S}_{2}\right.$ in the upper-left position). He was not a pioneer, but belonged to the second generation. In contrast with Bohr, Heisenberg, Schrödinger, Pauli or Dirac, he is not credited with any ground-breaking contributions. ${ }^{6}$ As the novel phrases it, Bloch made no comparable discovery (p. 158). But now, physics as such is entering a new stage, becoming a large-scale, coordinated organisation of "superlative efficiency" (p. 272), involving hundreds of physicists, each of them contributing an "infinitesimal share" (p. 271). The only way of making a difference under such conditions is to guide the field onto this new plateau of achievement, unleashing the era of big science.

The novel also addresses the metaphysical level ( $S_{1}$ beneath the bar), however. Quantum physics is symptomatic for a metaphysical crisis, affecting science and

\footnotetext{
${ }^{6}$ Although Bloch is generally regarded as a genius, the novel does mention "the relative slightness of his original work, the total absence of new fundamental discoveries or concepts comparable to those made or put forward by a number of his immediate contemporaries, such as Dirac, Heisenberg, Fermi, Oppenheimer, Schrödinger, the Joliot-Curies (p. 158/159). The name "Oppenheimer" seems a curious misplacement in this list, reflecting the ambivalence regarding the question whether or not Bloch/Oppenheimer is to be placed on the same level as these other 'giants'.
} 
society at large. Scientists see the "crisis of science" as "a reflection of the crisis that besets our whole society... How increasingly instable the integrations in physics are becoming" (p. 151). The "golden sphere of harmony" had already ceased to exist long ago and even the basic convictions (the philosophemes) of classical physics became untenable. Indeed, quantum physics exemplifies the "shakiness of our metaphysics" (p. 151), but also the "awareness of the need for synthesis". But this, according to Bloch and his followers, would require a shift, on the level of the philosophemes (beneath the bar: $\mathrm{S}_{1}$ ), towards dialectic materialism as the new foundation, turning society as such into a kind of university world, with physicists as guardians of the atomic age. According to Marxism, only a classless society may solve the crisis that science $\left(S_{2}\right.$ above the bar) experiences today (p. 151), abolishing philosophy by absorbing it into science.

Initially, the gadget has a positive impact on the subjects involved in terms of individuation and personal growth. It prompts and enables Sebastian to face difficulties that would have "overwhelmed him 3 years before", that he would have been "utterly incapable of coping with" (p. 178). Thanks to the gadget, he had "broken through that magic but sterilising cocoon of solipsism that had enveloped him ... He had become a human being" (p. 179). Yet, increasingly, this process of individuation becomes frustrated and Sebastian eventually emerges as a tormented subject $(\$$ in the lower-right position). Working on the bomb project, Sebastian experiences himself as "a man divided", outwardly self-possessed, but inwardly distraught and tormented" (p. 211). A "nameless anguish" possesses him (p. 213). His new symptoms (\$) are no longer the symptoms of egocentrism and unworldliness that troubled him in the past, for the "Thing" changes everything and engenders a series of more unsettling symptoms. He becomes increasingly distant and unapproachable. A sinister change comes over him (p. 256) due to his involvement in "this fearful Thing" (p. 257), turning him more and more into a stranger. In the confrontation with the Thing, the position of the scientific expert $\left(\mathrm{S}_{2}\right)$ becomes destabilised, and the research site becomes an ethical and epistemological clinic (\$), sometimes literally, when Sebastian is forced to keep his bed because of exhaustion (clinic is derived from $\kappa \lambda i \nu \eta$, = bed).

According to Tanya, his unsettling tasks make him inhuman and estrange him from humanity. His appalling responsibilities become "a screen separating them" (p. 260). The Monster creates "a gulf between them" (p. 288). "We've hit on the gadget... the Monster... the Thing" (p. 148), Sebastian argues, and this "Thing", this instrument of wholesale destruction, without parallel or precedent in history, is now relentlessly "challenging" him (p. 147). Indeed, his whole being becomes wrapped up in the Bolt; he eventually becomes devoured by it (p. 344). He is "consumed" by his gadget, his object $a$. The Monster will be born; nothing can stand in its way. His whole being seems to rebel against it, but he cannot stop the Monster. He senses that he is "in the grip of a necessity that transcended his own will" (p. 336). The object $a$ is pulling him towards his destiny. Face to face with the Bolt, he is no longer master in his own house, as Freud once phrased it:

He had known for a long time, even before the premonitory shadow of its shape first loomed before him, that his commitment to it was inescapable... His whole being rebelled, [but] the most important decision of his life was one that he had already unwittingly made (202). 
The gadget forces him to accept "a decision that he ... tried to justify as though it were a decision that he had freely chosen" (p. 339). Or, as he phrases it later in the novel: "I have no choice" (p. 364). As a result, he transforms into a chain smoking anorectic, becomes "terribly emaciated", ${ }^{7}$ but also his character changes. Still he cannot disconnect himself from the Thing, even if this implies a loss of integrity. For this is the morale of the story: Oppenheimer becomes what Lacan (1966, p. 870) refers to as a "victim of science" ( $\$$ in the lower-right position). Especially in fields such as theoretical physics, Lacan argues, an element of personal drama, a subjective toll is often involved. The crisis on the part of the subject entails a drama of knowledge that does not concur with the typical oedipal crisis in a classical Freudian sense. It is not a neurotic case of rebelling against the father (the Master), but rather an instantiation of becoming trapped in the matheme of desire $(\$ \diamond a)$.

\subsection{The Case of Communism}

The second instance of university discourse fleshed out in the novel is communism. Although communism is often regarded as an exemplification of absolute power, Lacan points out that, rather than reflecting the structure of a Master's discourse, it is a radical effort to replace the absolutist monarch by a rational, science-based system (with Stalin serving as an obscene version of the return of the repressed). Communism is social engineering and decidedly strives to be science-based. Dialectical materialism presents itself as a science (Engels 1880). In his book Materialism and Empirio-criticism, written in 1908, Lenin explicitly addresses the "crisis" in contemporary physics because physics is politics and vice versa (p. 252). Materialism is challenged, but not subverted, Lenin argues, by recent physical discoveries concerning X-rays, radium, and the like (p. 250). He intervenes in what for him is not a purely scientific debate (among trained experts), but a politico-scientific dispute between bourgeois physics and dialectical materialism. So-called "revolutionary" discoveries do not refute dialectical materialism, but rather confirm it. Even though in the case of electrons concepts such as matter and mass seem to evaporate, matter has not "disappeared" (p. 258), has not been obliterated by the onset of quantum physics. Lenin contests the conclusion (by Henri Poincaré and others) that the very possibility of "knowing the object" evaporates in the case of subatomic particles such as electrons (p. 254). According to Lenin, the crisis rather stems from the fact that these new developments threaten to reduce physics (which

\footnotetext{
${ }^{7}$ Descriptions by fellow scientists collected by Thorpe and Shapin (2000) likewise emphasise the "fragility of the smallness of his body" (p. 553). Oppenheimer is portrayed as "frail to the point of transparency", as "almost ethereal". The thin, ascetic Los Alamos Director looked like a fifteenthcentury portrait of a saint (p. 552). He was so thin that he seemed "a disembodied spirit", "lacking a fleshly dimension" (p. 552). His emaciation suggested "an aversion to incorporating the world". In his autobiographical account of their friendship, Chevalier describes him as the archetypal ascetic and associates his "surprisingly blue eyes" with "the faces of apostles... A kind of light shone from it" (Chevalier 1965, p. 11).
} 
had always been an emancipatory field) to a mere utilitarian artifice, a technological recipe for manipulating nature (p. 256). For Lenin, there is no real "crisis" at all. The bourgeois philosophy (articulated by Ernst Mach and others) is based on a misinterpretation of the new physics, to be rebuked by dialectical materialism. Lenin sees himself an engineer of power, and therefore his vocation is to address scientific (and ultimately philosophical) debates as well. Unlike Machiavelli, he is not a scholar-servant $\left(\mathrm{S}_{2}\right.$ in the position of recipient, serving a Master, an absolute monarch), but a political engineer $\left(S_{2}\right.$ in the position of agent) for whom dialectical materialism is a scientific project, concurrent to physics. Therefore, the crisis in (bourgeois) physics (represented by bourgeois authors such as Mach) must be addressed in the same manner as the crisis in (bourgeois) politics and (bourgeois) political economy, namely by pointing out that its contradictions can only be sublated by opting for a truly scientific (i.e. dialectical materialist) approach, building on Marx and Engels (notably the latter's Anti-Dühring).

A communist society purports to be a new type of society where science holds sway. As Žižek phrases it, building on Lacan: "the Soviet Union was the pure reign of university discourse". ${ }^{8}$ Marxism (dialectical materialism) appeals to scientists in the novel precisely because it is structured like university discourse. It entails a rationalistic, scientific approach to politics: it is a science. Due to Marxism, a formerly unworldly Sebastian suddenly becomes aware of the contemporary world. He begins to read newspapers, listen to the radio and explore contemporary history, politics and economics. As a communist convert, he overcomes his introvert, neurotic inhibitions and connects with the world at large. Before that time, he lived solely for the atom (the quantum world), but now he discovers that the macro-world is open to science (dialectical materialism) as well. He devours all three volumes of Das Kapital in the original over a weekend (p. 70). Although for strategic reasons party officials refuse to let him actually become a party member, Sebastian meets with the Berkeley "unit" regularly, acting in every way as though he were a bona fide member, and the other members so regard him. A time may come when it will prove of great advantage that he never was in fact a member, his party superiors argue. But no one is going to prevent him from regarding himself, in his own mind and conscience, as a true "communist" (p. 15).

The Bomb aligns quantum physics and dialectical materialism even more closely. As the United States are manoeuvred into the war with Nazi Germany, the bomb becomes the thing most likely to decide the outcome. For communist scientists, both dimensions of their compartmentalised existence can now be brought closer together: having worked to sovietise the United States, they can now wholeheartedly contribute to the war effort, albeit in the expectation that eventually, the bomb will come under international control, through an international atomic agency controlled by (communist) scientists. Responsibility over the Bolt should not rest with any particular government, they argue, and scientists should have a major voice in determining the use to which it is put (p. 216). Thus, as they join the army of scientists to make their infinitesimal and anonymous contribution $\left(S_{2}\right.$ in the upper-left

${ }^{8} \mathrm{http}: / /$ www.lacan.com/zizfour.htm 
position) they are nonetheless spurred on by a demanding worldview, whose conflict with the political status quo is temporarily suspended $\left(S_{1}\right.$ in the lower-left position).

They work on an unprecedented, unimaginable something ( $a$ in the upper-right position), a genocidal weapon of mass destruction, meant to destroy whole cities in a few seconds. This gives rise to hesitance and doubt, resulting in meetings concerning the social implications of the gadget ( $\$$ in the lower-right position). But, as the novel phrases it, this is not a time to indulge in the private luxury of qualms of conscience (p. 147, p. 152). Joining the communist party is like "taking holy orders": entering a world that separates its members "from all those who do not belong to the brotherhood" (p. 80). Joining the scientific Valhalla kolkhoz confirms and radicalises their conversion (their willingness to identify completely with $S_{2}$ at the expense of all other societal ties).

But as soon as the gadget is successfully detonated, the happy concordance between science and politics becomes disrupted. Germany has already surrendered (and never seriously worked on developing an atomic bomb), while Japan is about to surrender as well. There is, according to the novel, no justification anymore for using the bomb. The bomb basically becomes something completely different: a sign of warning addressed to Russia. The bomb will redefine global politics in the post-war era: will play a decisive role in a budding anti-communist conflict with the Soviet Union. Oppenheimer frantically tries to secure his say over the future of the bomb, even if this means giving the names of former communist friends and denouncing colleagues to security agents, who constantly harass him to do so. Eventually, he reverts to a damaging "fabrication" (p. 338, p. 377, p. 406, p. 436, p. 445), tangling himself up in a whole maze of fabrications (p. 344), but he is no longer considered irreplaceable and his pre-war politics make him highly vulnerable $(-\varphi)$. While science (the gadget, the object $a$ ) initially transformed warfare, it is now the other way around: the military is rapidly transforming science, increasing its power by subsidising universities for research, while many left-wing scientists and Valhalla veterans are refused instalment in their university posts, because of their tainted records. The hand of the military is "everywhere". While normal science is reinstalled ( $S_{2}$ in the upper-left position), many scientist are expelled from academia, forced to leave the field, meanwhile plagued by moral misgivings because of the nuclear cataclysm to which they contributed, the "holocaust of horror", the "mega-deaths" (p. 202) to which two major Japanese cities had been exposed (\$ in the lower-right position).

As the atomic bomb becomes technologically reproducible, an item of "mass production" (p. 433), the scientists feel decidedly used. Their knowledge is appropriated and they themselves become discarded. They have "equipped the army with the absolute weapon, a wholly new factor in the world situation, a force that had no parallel in history", serving "humanity's mania for self-destruction" (p. 338), but now they are dispatched (as human resources) while the State seizes hold of the valuable product of their labour. This scenario would have been unthinkable without a third instance of university discourse: the secret intelligence service. 


\section{6 $S_{2}$ as Secret Agent}

Quantum physics is initially pure research, as we have seen, and quantum information is allowed to circulate freely within the international scientific community, between the German-speaking and the English-speaking world. But as soon as it is discovered that uranium isotopes may unleash a nuclear chain reaction, so that they may in principle be used for making nuclear bombs, this type of scientific information becomes "classified information" overnight, that is: classified as "confidential" or even "top secret". Classified is a metonym in the Lacanian sense of the term: a seemingly neutral adjective actually referring to a problematic shift, with serious implications for the scientists involved. Scientific information that is regarded as "classified" no longer belongs to the commons of free-floating ideas, but becomes compartmentalised. The term "classified information" is a metonym because an apparently neutral, technical term (to classify) is used to indicate that this type of information is potentially dangerous or even toxic from now on, and must therefore be handled with utmost care. Suddenly, $S_{2}$ is confronted with information (neutral and innocent until now) which, by being stamped as classified, is transformed into something highly valuable and dangerous, into an object $a$. Psychoanalytically speaking, this constitutes an instance of sublimation: something apparently unexceptional (scientific information) suddenly becomes highly exceptional. Classified means that the information is "classified as...", namely as highly confidential or even top secret. The metonym "classified" indicates that information which formerly belonged to the scientists themselves is now appropriated by the state. It no longer belongs to the scientists who produced it. Quite the contrary, the formal labelling of certain data as confidential implies that new forms of misconduct are introduced: leaking classified information, a confidentiality breach which may incur serious penalties for the scientists involved: the producers, but no longer the owners of this information. Moreover, a formal security clearance is from now on required to be allowed access to classified data and to handle classified documents. Classified or compartmented information is nonetheless bound to "leak". Such leaks must likewise be regarded as an inevitable part of the confidentiality complex, for it is only by labelling information as highly confidential that it can be leaked at all and that the desire to leak can emerge, so that the $\sin (\dot{\alpha} \mu \alpha \rho \tau i \alpha)$, the misconduct can be committed. As explained by Saint Paul, sin and desire result from prohibition, rather than the other way around. ${ }^{9}$ Secrecy requirements, indeed: the very label "secret" turn neutral activities (sharing information) into perpetrations. Due to the label classified, sharing information becomes leaking or funnelling information: a new type of misconduct, a by-product of the new constellation ( $\$$ in the lower-right position). But precisely because of the value which this information suddenly acquires, scientists may feel forced to leak it, in response to a compelling force majeur, such as:

\footnotetext{
9"I would not have known what sin was had it not been for the law. For I would not have known what coveting really was if the law had not said, 'You shall not covet"' (Romans 7:7; cf. Lacan 1959-1960/1986, p. 101).
} 
preventing a U.S. monopoly on atomic weapons. In other words, researchers fall victim to the matheme of desire $(\$ \triangleright a)$. Classified information becomes the object $a$ precisely because it is classified as top secret, withdrawn from the knowledge commons.

This has grave repercussions for the individuals involved. As soon as it becomes clear that atomic knowledge may give rise to an atomic bomb, the biographies of the scientists involved (previously uninteresting more or less) become "records" or "files", while problematic entries (such as: involvement in certain political activities) become items of concern. Thus, from now on, scientists involved in classified research are scrutinised and monitored. A researcher with communist leanings is from now on a scientist with a divided loyalty (p. 312), who "professes loyalty first and foremost to the Soviet Union" (p. 229). The communist is the Mister Hyde $(\$)$ concealed beneath the allegedly impassive expert persona $\left(S_{2}\right)$, who is therefore likely to fall victim to the matheme of desire and to give in to the inclination to perpetrate. When Sebastian is about to be appointed as scientific director of the Valhalla project, it is made clear to him that "from here on ... you will have to resign yourself to the fact that you'll probably be under more or less constant observation. I would simply assume that everything you say, and everything said to you, whether directly or over the telephone, is being monitored, that your mail is being opened and your movements followed... You'll be watched closely" (p. 217), all this because of his involvement with the Thing. Due to the Thing, Sebastian becomes a file, scrutinised by secret service experts, trawling it for symptoms of divided loyalty.

Thus, Sebastian becomes the target of investigations by the secret service, but the object of these investigations is not Bloch as a living human persona, but something inside Bloch, something enigmatic: the "Mr. Hyde in this Dr. Jekyll" (p. 40) as Gregg phrases it, his communist leanings, in combination with his uncanny gift for influencing people, his almost "telepathic" talents of persuasion, bordering on the occult. Bloch is an enigma (p. 68) who does not limit himself to one particular speciality, like normal scientists, but seems completely at home in the whole realm of science; and in the arts as well (p. 40). ${ }^{10}$ There is something strange about his eyes and voice, moreover, and his face seems suffering and haunted: a "strange, arresting" face with a "brooding, uncanny look" (p. 67), a "demoniac look" (p. 258), with a compassionate yet cruel set of eyes (p. 67). Due to his involvement with the Thing, his face becomes even more unsettling: an "abstract mask" (p. 261), while his "black eyes become enormous" (p. 343).

For Gospodin Gregg, the archetypal secret agent, this enigmatic "something", the Mr. Hyde in Dr. Bloch, the $\$$ inside $S_{2}$, becomes the object $a$, to which he devotes many years of research and around which he designs a completely new type of "experiment". Gregg is a psychologist studying a physicist, driven by his anti-

\footnotetext{
${ }^{10}$ In art a similar dynamics is discernible as in science, Sebastian argues. Beginning with Cézanne, modern painters had "destroyed painting ... had begun the process leading to disintegration that made the exhibits of modern painters look like the cemeteries and ossuaries of art" (p. 147/148). The monster exemplifies this disintegration of "substance and sense" (p. 201).
} 
communist zeal, his patriotism $\left(\mathrm{S}_{1}\right.$ in the lower-left position). In terms of university discourse:

\begin{tabular}{c|c}
$\mathrm{S}_{2}$ (Gregg-the-psychologist) & $a$ (the Mr. Hyde in Dr. Bloch) \\
\hline $\mathrm{S}_{1}$ (patriotism) & $\$$ (Bloch as an obsession)
\end{tabular}

Bloch exerts an indefinable, telepathic influence upon others, and Mark's assignment, acting as the Chief's eyes and ears (his equipment as it were) is to find out what it is:

But there was another man in Sebastian Bloch ... It was he who fascinated the Chief to the point of obsession and whom he had singled out for his quarry... the mystery behind those eyes was not the mystery of innocence (p. 159).

Gregg sees Oppenheimer/Bloch as an enigma who manages to exert a "poisonous influence" (p. 165) on "hundreds of people" (notably students and young researchers), and the investigation aims to reveal the secret of his magnetic personality. To achieve this, Gregg wants Ampter to build up a file. Modern wars, Gregg explains, call for complete mobilisation of manpower and resources; and this especially involves mobilisation of "brain power" (p. 38). Modern wars are won or lost in laboratories, and this creates wholly new security problems. For while statesmen are trained in the game of international politics and the military in the game of war, "these science fellows know nothing about either. And some of them have some pretty wild-eyed notions". The first objective is to find out whether Sebastian is a communist. But the target is not a naïve subject. From the very beginning, Sebastian was "conscious of another presence of whose attention he was the object" (p. 221).

This dimension of the novel likewise reflects the dynamics of university discourse. The secret service agent is an expert, a researcher, specialised in accumulating and analysing files (with the help of recording equipment, typewriters, archives, mnemonic devices, etc.). The name Ampter is reminiscent of the German word Amt, originally spelled as Ambt. Etymologically speaking, the word basically means servant. Mark Ampter is the agent (a promising professional, yet replaceable, in principle) who is expected to spend all of his time on investigating Bloch, in order to discover the mysterious factor X somehow at work in him, by producing a huge pile of material about his target. Years of work result in an impressive file, the Bloch archive, "a stack of folders ten or more inches high" (p. 157). As Gregg later explains, it is a unique procedure, "something of an experiment" (p. 239). Via Mark Ampter (his instrument, his eyes and ears), Gregg aims to become connected with, to establish a window into the doings of Sebastian Bloch. The Chief from now on perceives everything Ampter says as a possible access to "the mind of Sebastian Bloch" (p. 73). Gregg is basically a psychologist who has designed an N = 1 experiment, keeping his distance, working from a distance, using Ampter as his one-way screen: his "one direct line right into the heart of the enemy territory" (p. 159). Ampter is entrusted with the actual work, but Gregg reads his reports quite care- 
fully, looking for key symptoms, in order to develop a psychological assessment, leading to the conclusion that Bloch is indeed a major security risk, a "very dangerous man" (p. 241).

But it is impossible to tell exactly wherein the danger lies. The Mr. Hyde continues to elude him. While Ampter is beset with serious "misgivings as to the validity of his highly confidential mission" ( $\$$ in the lower-right position), Gregg becomes increasingly "obsessed" with Bloch. During the first 5 years of the research, Gregg himself never even sees or meets Bloch. And yet in a sense he "knows him more intimately than he had ever known a human being" (p. 268). He comes to the conclusion that "there was in this man, in spite of his almost godlike gifts, something negative, something destructive, something against nature ... a dangerous force" (p. 268). Gregg becomes a Bloch expert, studying his case for years, but still struggling to explain what the dangerous factor amounts to. On the one hand, Bloch is one of the elect, but at the same time he is a dangerous apostate. Bloch is completely absorbed by his work, but what is "the secret of that compulsion" that drives him (p. 315)? Gregg confesses that, "with all his knowledge of human nature ... the mystery still eluded him" (p. 315). Bloch, or rather: this elusive something at work in Bloch, is Gregg's object $a$. When he finally meets Bloch, he is intrigued even more. Bloch looks decidedly "unreal". He reminds him of "a piece of sculpture dug up after many centuries and showing the mark of time" (p. 310), "the reincarnation of some holy man out of a remote century" (p. 315); the Ötzi of the intelligence service.

In order to come to terms with the enigma, Gregg decides to design a "trap", a psychological mouse trap (p. 408), similar to the one designed by Hamlet. He orders one of the scientists who works as a secret agent to tell Ampter that German scientists (allegedly farther advanced than the Americans) had decided not to build their bomb after all, and are now eager to contact Bloch, in order to convince him to do the same, so that the whole genocidal project can be put on hold: a self-imposed international moratorium on nuclear warfare as it were, initiated by scientists who bypass their governments. Ampter is unable to contact Bloch, and therefore reluctantly informs Tanya, who (again: reluctantly) informs Sebastian, who is indeed "tortured" by the story, because he cannot decide whether it is true. He has the uneasy feeling that the story is "a lure", "a trap" (p. 288), and Tanya soon realises that "she shouldn't have mentioned it" (p. 257), for (the Lohengrin-complex again) her wild swan now withdraws even more into his increasingly "forbidding" (p. 259) world of "inaccessible thoughts" (p. 364), where no one can reach him. He is "inexorably carried toward a cold, high region" (p. 232). In fact, this conversation practically ends their marriage (the Lohengrin-motif indeed). Their relationship is disrupted because Tanya cannot refrain from saying something which should have remained unsaid. From a security perspective, spreading such a story means sabotage, an attempt to slow down the progress on the bomb.

In a communist, totalitarian society, the whole state is transformed in a laboratory, and Gregg adheres to this same logic: his war against totalitarianism relies on monitoring and manipulating seemingly innocent individuals, in order to expose them as agents, as security threats, thereby becoming totalitarian itself. His secret 
service becomes a totalitarian, science-based state within the state, studying, but at the same time mimicking the logic, the functioning of communism. Communism and the secret service increasingly mirror one another. Bloch's role in the novel inevitably changes, as a conceptual physicist is transformed into a research subject, enrolled in a psychological $\mathrm{N}=1$ experiment.

For Bloch, the hovering, ubiquitous presence of secret agents generates a sense of profound, almost paranoiac "uneasiness" (p. 221). After many rounds of interrogations, which increasingly revolve around the story about the German scientists who allegedly tried to contact him, Bloch finally confesses that he had the story from Ampter; thereby contaminating the latter's record and destroying his prospects for a university career. But somehow, he cannot do otherwise, he feels completely powerless and forced to comply $(-\varphi)$. Refusal to give in would mean becoming disconnected from the gadget:

Sebastian knew that he himself had just lost a little piece of something precious and irreplaceable, and that he was about to lose more. And he knew that he was helpless to prevent it (p. 227).

Gregg subsequently exposes Ampter to the tape-recording of Sebastian's voice mentioning Ampter's name; an extremely uncanny experience: "the voice was Sebastian's, but it wasn't Sebastian speaking. There was something inexorable about it" (p. 438). This voice (which once had been Mark's source of inspiration) now became the source that entered the damaging fabrication into Mark's file. The voice he had missed, the voice he loved and longed to hear, is all of a sudden there, but detached from the body as a whole, and transformed into a toxic, damaging voice. In the course of the twentieth century, Lacan (2004; cf. Zwart 2017a) argues, the human gaze and voice, as objects $a$, as objects of desire, had become externalisable and transferrable with help of cameras, voice recorders and similar devices. Although nowadays we have sufficiently familiarised ourselves with such techniques (such externalisation), they were initially experienced as fairly shocking: evoking both fascination and concern. For indeed, what used to be natural and familiar ('heimlich,' namely eyes, voice, etc.) became technologically reproducible, became uncanny. And although gradually people familiarised themselves with dislocated faces and voices, the confrontation with this particular recording reveals once again the estrangement of the original situation when, via Edison-like devices, a disembodied but still recognisable voice became audible for the first time. It is precisely the fact that the voice is disembodied and recorded which makes it so damaging, turning the recording into a record, a vital piece of harmful evidence. The recording of the recognisable yet disembodied voice is the object $a$ of the Bloch file, the missing link which is now there, so that the file is by now "quite complete" (p. 440). As Gregg explains: "I've been working on the case for eight years. I'm tempted to say that I know more about Sebastian Bloch than I do about myself (p. 440). Gregg is referred to as "a cool precision instrument of a mind" (p. 440) able to "dissect" the mind of Bloch, via constant surveillance, in combination with traps. 
But to really discern the Mr. Hyde in Dr. Bloch, Gregg has to make a decisive turn, opting for a different type of discourse, based on the Freudian credo that, in order to understand a certain case history, we have to know and record everything, however trivial, embarrassing, etc. it may seem. As Freud himself phrased it: "We instruct the patient to ... report to us whatever internal observations he is able to make [taking care not to] exclude any of them, whether on the ground that it is too disagreeable or too indiscreet to say, or that it is too unimportant or irrelevant" (1917/1940, p. 297; cf. 1926/1948, p. 214). Seemingly trivial details (the bagatelle) may prove to be highly significant. Unconscious motives are revealed by failures and embarrassments, rather than by achievements. But this same rule now guides the work of Gregg, aimed to bring to the fore the hidden hysteric $(\$)$ in the allegedly impassive researcher $\left(\mathrm{S}_{2}\right)$, forcing Bloch and Ampter to confess not only what they know but also what they do not know themselves about themselves. Gregg's method probes divided subjects (potential apostates) to take the floor and reveal themselves. He opts for a kind of talking cure: inviting Bloch and Ampter to give themselves away merely by speaking, by asking seemingly innocent questions. In the case of Bloch, such interrogations give rise to tics, fatigue, spinal ailment, incessant smoking, fabrication, and other symptoms of imbalance: because Gregg the psychologist manages to confront him with his object of desire, his fatal flaw. But before diving more fully into the discourse of the analyst (into which university discourse is inevitably sliding at this point, taking a quarter turn to the left) I will first of all explore the role of the discourse of the hysteric in Chevalier's novel.

\subsection{The Discourse of the Hysteric}

Although the novel first and foremost revolves around the intricacies of university discourse, as we have seen, the discourse of the hysteric (in the Lacanian sense of the term) occasionally flares up as well, both on the individual and on the collective level, for instance when qualms of consciousness can no longer be contained or repressed. In the latter case, the hysteric's discourse gives rise to a boisterous attitude, challenging the authorities, criticising those in power: $\$ \leftrightarrow S_{1}$ on the upper level. In the full version:

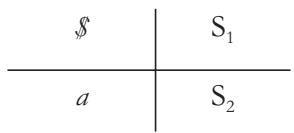

It is a basic objective of university discourse to convert untrained individuals into impassive, reliable experts $\left(S_{2}\right)$, a process referred to by Bachelard (1947) as the formation of the scientific mind. A similar objective is at work in Marxism (dialectical materialism), aiming to transform anarchistic, hysterical and utopian forms of protests ("childhood diseases" of the leftist movement, as Lenin once phrased it) 
into objective science, i.e. to transform the discourse of the hysteric into a wellorganised and science-based university discourse, represented by the impassive communist apparatchik as agent $\left(\mathrm{S}_{2}\right)$. From a Marxist perspective, the intended sovietisation of the United States is meant to be a thoroughly scientific endeavour.

Nonetheless, as we have seen, university discourse produces instances of discontent and deception (\$), for instance when the bomb was used not as a weapon against Nazi Germany (as many scientists, especially refugees from Central Europe, had hoped), but rather as an instrument of power to secure the global monopoly position of the United States. Scientists were expropriated, as the bomb was suddenly out of their hands and out of their control. As a consequence, forms of protests against nuclear warfare policies (against the bomb) began to emerge amongst scientists, and discontent took the floor. In the novel, they also express their disappointment in the father of the bomb, former mentor Bloch, now spending most of his time in meetings with politicians, generals and representatives of "the highest circles of industry, business tycoons, presidents of investment trusts, owners of newspapers and press syndicates, men who control finance, media and transportation networks, in short: the very people whom, as a Marxist, he had regarded as the enemy; for they are all attracted by the Monster" (p. 283), paying tribute to the Monster and its maker in a "fetishist way" (p. 285). In order to stay connected with the gadget, with the fetish he produced, Bloch has to follow it into this bourgeois world, even if it means detaching himself from his former environment. In retrospect, Sebastian now regrets his former engagements and sadly admits that his communist sympathies had been a mistake, that the Communist Party had "remained alien and unassimilated", speaking a "strange language" (p. 234). He also drifts out of his marriage. It is via the newspapers that Tanya finds out that her husband has "suddenly become worldfamous" (p. 359) as the "man of the hour" (p. 368). For former students he is not only unapproachable, but also unfathomable, a mystery more than ever, moving in the "most exalted spheres", having a voice in the "highest councils of the nation" (p. 413), but consistently failing to speak out; or to take a stand against what is happening: the expropriation of (the know-how to produce) the bomb by politicians, big industry and the military. The demise of their former mentor is considered a symptom of the times. As one of his former students phrases it during a protest meeting: "There's something wrong with our civilisation" (p. 385); a perfect articulation of the experience of discontent.

Mark Ampter is one of these protesters, but tries to professionalise and institutionalise the discontent. To avoid the discourse of the hysteric $\left(\$ \rightarrow S_{2}\right)$ he becomes hyper-active, travels to Washington as executive secretary of an association of leftwing scientists concerned about the future of the Bolt. The Bolt has "corrupted" and "poisoned" science (p. 412), and this must be undone. Science must regain its innocence. He writes and publishes manifestos, bulletins, leaflets, press releases and letters with the help of duplicating machines, dictating machines and telephones, and even gives "bolt physics courses" to government officials. From all over the country scientists, including the most eminent, drop by to offer their help, but "never Sebastian" (p. 413). All the while, the scientific community is eagerly awaiting the publication of a plan drafted by a powerful commission of which Sebastian is the 
most articulate and prominent member. When the document finally appears, in tens of thousands of copies, the mystery seems solved. A moratorium on nuclear warfare is proposed, and the gadget is projected as a potential servant of humankind, a device that may prevent all future wars. But left-wing scientists are suspicious readers and before long they recognise the "trap" (p. 422). The offer of a moratorium is a smart plan bereaving the Russians of their opportunity to develop a gadget of their own $(-\varphi)$, a "disguised hostile act" (p. 424), a political calculation. In short: "Now we know where Sebastian stands" (p. 425).

But Mark Ampter finds it impossible to accept this outcome. In order to escape from this deadlock, he opts for a different strategy: the discourse of the analyst. Instead of criticising those in power, he sets out to seek the truth, shifting the object $a$ into the position of the agent (upper-left position). He finally wants to come to terms with the situation by exposing himself to a painful truth. He decides to visit his former Chief Gregg, who has been promoted to the position of highest secret service official, and meets him in the heart of darkness in his empty office, deprived of all personal paraphernalia, reflecting Gregg's "almost pathological reluctance to reveal himself" (p. 435), in accordance with the imperative $\$ \rightarrow S_{2}$ (the desire to become a thoroughly impassive functionary). Gregg, the observer, does not want to be observed himself, let alone give himself away.

To dig up the truth they descend into the basement, the secret service's "laboratory" (p. 437), replete with instruments and machinery, containing an immense collection of tapes: derogatory information about thousands of individuals. Here, the tape is stored with Sebastian's voice on it, so that Mark is finally exposed to the uncanny truth. The source of the derogatory information, thwarting his career, but also the cause of his physical impairment as a soldier (the loss of a significant part of his intestines, the loss of his masculinity and strength: $-\varphi$ ), was Sebastian himself: the very person about whom Mark had produced a large pile of derogatory information himself. Mark had tried to transform himself into a secret service apostate, had converted to communism and had joined the army. Because of his tainted record, however, he was deployed in extremely dangerous positions, ending up severely wounded, physically marked for life. He had hoped that Sebastian's gadget would have ended the war, and this idea (that Sebastian was working on the gadget) had been his "talisman" (p. 320): the very thing (a distant thing, still inexistent, a phantasmagoria perhaps) that kept him alive. Suddenly, he had an experience of doubt, and the idea that "the gadget would not be forthcoming after all produced in him a creepy feeling of panic" (p. 320). And precisely at that point he enters the shallow cave where "a big part of his guts" are shot away. He survives, becomes a medical miracle, an "exhibit", a "guinea pig" (p. 367), but like Sebastian he suffers a profound physical change. The damaging information, and the loss of his talisman, more or less dismantles him. Notably, he loses his strength. His pre-war suits are much too big for him (p. 383) and he is no longer able to lift heavy weights (p. 385). Unable to listen to the tape recording of how Sebastian's disembodied, uncanny voice is giving the names of former colleagues, students and friend, Mark tries to get away, but Gregg seizes his arm with "a powerful, cruel grasp" (p. 438). Mark "tries to wrench his arm free" but Gregg holds it "in an iron grip", confronting 
him with his post-traumatic fragility, so that he is forced to listen to how Sebastian's voice, in response to Gregg's urgent question ("I want to give you the name of that intermediary"), finally replies that it was "Mark Ampter" (p. 439).

In this scene, we enter a different type of discourse, a different kind of interaction: the discourse of the analyst. Mark, the former professional $\left(\mathrm{S}_{2}\right)$ who tries to rehabilitate himself, is exposed to the object of desire which sets everything in motion (a), his conversion to communism as well as his impairment on a Pacific island: Sebastian's disembodied voice, confronting him with an unsettling revelation, something which seems impossible to grasp or work through: the secret service "laboratory" as a traumatic couch.

\subsection{The Discourse of the Analyst}

The novel is a discursive clinic, enabling a diagnostics of modes of discourse. To bring these discourses and their contradictions to the fore, the novel is a stage, a Bühne, where various types of discourse can be fleshed out and mutually exposed to one another. To achieve this, the novel adopts a psychoanalytical perspective. Quantum physics gives way to psychoanalysis and self-analysis. ${ }^{11}$

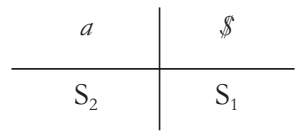

The true protagonist or agent of the novel (spurring the others into action, while frustrating their plans and ambitions) is the object $a$, the gadget, the thing which inevitably draws the other characters into various courses of action, and hundreds of scientist into the Valhalla kolkhoz, where they become subjected to compartmentalisation, isolated from the outside world, accepting a "voluntary censorship on atomic information" (p. 119), keeping information "out if circulation", in accordance with "the security principle of compartmentalisation" (p. 208) which enforces "a strict observation of the rules of secrecy and compartmentalisation" (p. 272). The gadget deflects the life-course of all those who come within its orbit. Like a fetish, it draws scientists, politicians and industrialist towards it.

The Bolt has an enormous impact notably on Sebastian himself (allegedly the "father" of the Bolt). As soon as he becomes involved with it, Bloch's character undergoes "a profound change" (p. 381). He makes "a complete about-face", "disavows all his former beliefs" and even turns "informer", as we have seen. He not only tells on former comrades, but even invents "highly compromising stories" (p. 381) regarding Mark. Indeed, "the Monster haunts him" (p. 183). The Bolt

\footnotetext{
11 "Those of us who seem to the world at large to be the most disinterested - I mean scientists ... are actually concerned with ... man's relation to himself" (p. 30/31).
} 
proves a poisonous entity, affecting his integrity, addressing and challenging everybody (the object $a$ now in the upper-left position as agent), scientists first of all, but also generals, administrators and businessmen. Those who come too close, who fail to keep their distance, are put out of balance, become derailed (\$ in the upper-right position). This notably applies to Bloch. A devoted, pure scientist becomes a security risk, a fabricator.

But the change even goes much deeper than that. It speaks through his body, a suffering body, a "bony frame", a "wretched thing" (p. 347), an "island of pain" (p. 229). He becomes increasingly conscious of the "fragility" of "this flimsy, faulty organism that he carried about with him" (p. 377), of his "precariousness" (p. 377). Notably, he suffers from a chronic spinal ailment. His back aches "excruciatingly" (p. 224): he is tormented by "an excruciating strain on his back" (p. 228), especially when he is interviewed by secret service agents, which frames him as an American Prometheus. The pain in his spine becomes "unremitting" (p. 321). Towards the end of the novel he looks frightfully emaciated and frail (p. 310, p. 343). He does not want Tanya to see him naked because he has grown so thin (p. 347). He has become "a shadow of his former self ... The brain was still there .... But of the rest: what remained?" (p. 323). Indeed, his body has become a body "without organs" (Deleuze and Guattari 1972). His head is described as "a little knot of hardness ... prolonged by an awkward spine, to which an odd assortment of organs and parts was attached", not as functional integrated parts, but "each of them a point of attack for discomforts" (p. 135). He seems a kenotic subject, "emptied of all his substance" (p. 296), smoking cigarette after cigarette (three packs a day), a fragile envelop of vessels and arteries (p. 230). As if his body is taking revenge for his desire to strip his life of everything but the essential, sacrificing everything to his relationship with the gadget, thus falling victim to the matheme of desire $(\$ \diamond a)$. Sebastian becomes an emptied, kenotic subject. ${ }^{12}$

Due to his attachment to the gadget he becomes an unapproachable "total stranger", to Tanya (p. 362), but to his former colleagues and students as well. Because of his unconditional devotion to the Bolt, Sebastian resolves "to forgo all sexual indulgence", to "harden himself against her" (Tanya), as an act of "renunciation" (p. 334), exemplifying Freud's concept of Versagung. He and Tanya hardly ever sleep together, but when at a certain point they do, she notices his dramatic metamorphosis, his transfiguration, becoming aware of him as "a shivering presence in the bed ... an icy chest, an icy shoulder" (p. 306). Indeed, "the contact with hard bone covered with cold, clammy skin was, for a second, repulsive". But then she experiences some tenderness for "this frail, vulnerable being - a mere skeleton covered with skin and hair... She pressed herself against him, enveloped him with her flesh, the fullness and the firmness of the matter that composed her body, the sheath of muscle and tissue that clothed her bones... He was taller than she, but he now weighed considerably less than she did... He felt so small and frail and insub-

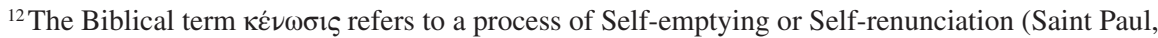
Letter to the Philippians 2:7, where it is said that Jesus 'emptied himself' (of His previous, divine Self; Cf. Zwart 2016a).
} 
stantial, it was almost like clasping a naked undernourished little waif (p. 306/307). In short, she experiences his "too-light, clammy, bony weight" (p. 307) as decidedly uncanny.

Sebastian makes the Bolt, it is his Monster, but the gadget drastically remakes him too. It seems as if Sebastian's face is “marked by some searing vision, by some soul-shaking revelation" (p. 400). Chevalier's description of Sebastian's face, marked by his encounter with the Bolt, is remarkably reminiscent of Jung's description of the impact of the Trinity Vision on the body, personality and face of Brother Nicolas of Flüe, after being confronted with a revealing vision that dramatically changed his life, but ruined health (Jung 1953, p. 78). The confrontation with this inexplicable, overwhelming something unleashes a process of kenosis and metanoia.

Towards the end of the novel, Sebastian's state of chronic "exhaustion" (p. 346), due to his interactions with the Thing, results in a physical and mental breakdown, a kind of "stupor". As Tanya phrases it, Sebastian had been "wearing himself out" (p. 250), had "burned himself out" (p. 428). Finally, there is an experience of revelation. Sebastian finally discerns a pattern, a higher plan in everything, a fatality that carries not only his "aching" body, but the whole world, as on a current. He feels dreadfully alone and yet he seems to embody all mankind. As if he had acted as the instrument of an "inexorable necessity" (p. 446), of a "fatality that was carrying him" (p. 446), and this new insight illuminates everything for him. He will vanish as a person, but his spirit will "hover over men", helping them "to illuminate the formulation of a theorem" for instance (p. 447). "Wherever men are gathered, in meditation, in council ... he would be the faith, the inspiration ... he would be nothing and all (p. 447)". In Jungian terms, he experiences a psychic "inflation", identifying himself with the archetypal spirit. Shortly after this vision, Tanya decides to leave him, claiming that he has become "inhuman" (p. 449).

What precisely happened to Sebastian Bloch, psychoanalytically speaking? He represented the Lohengrin-complex, but he also incorporates the Icarus-complex: a stellar career, a science celebrity, ready to take enormous risks, eager to reach unprecedented heights, but then he "flies too high" (p. 123) so that he is destined for a dramatic fall. This concurs with the basic message of the sizable mural (on wooden panels, almost hundred square meters in size) painted by Pablo Picasso in 19571958 for the UNESCO headquarters in Paris, which came to be known as The Fall of Icarus. ${ }^{13}$ There is a stark contrast between the fleshy, bathing, living, healthy bystanders and Icarus himself: a minimal human being, stripped down to his bare essentials, so that only a skeleton remains, as if his body has been exposed to radiation and transformed into an X-ray picture, about to drown. Bystanders witness how Icarus is about to disappear from view. Picasso himself persistently refused to comment on the meaning of his artwork, but many connected it with the nuclear bombs which put an end to World War II, as UNESCO was established in response to the

\footnotetext{
${ }^{13}$ Picasso himself referred to it as "Humanity turning its gaze towards the happy future" (Cabanne 1977, p. 487). Georges Salles, honorary director of French Museums, dubbed the artwork The Fall of Icarus in his inaugural speech (Di Lauro 2004).
} 
prospect of global nuclear devastation..$^{14}$ The Fall of Icarus is the portrayal of a human being whose flesh is obliterated (by uranium-235?) so that his bare essentials are exposed.

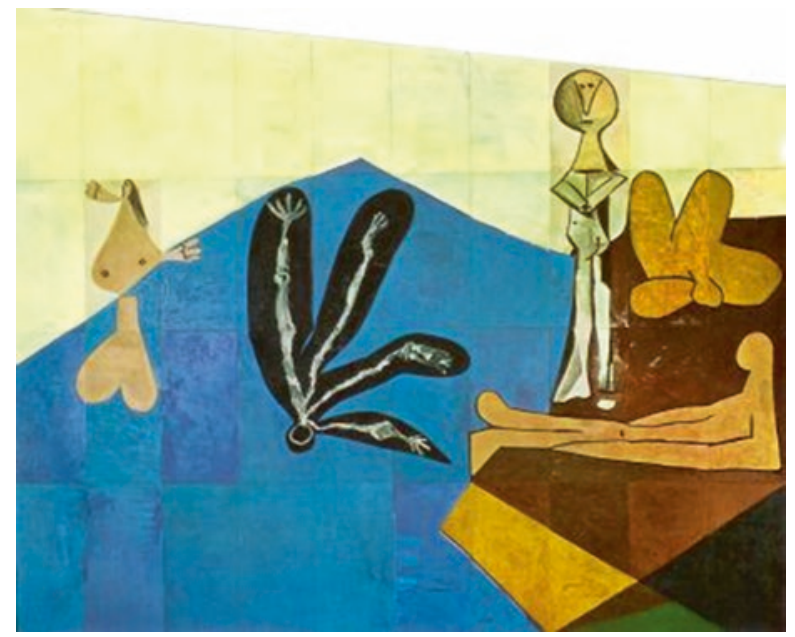

Towards the end of the novel, during the catharsis or denouement stage, Gregg points out that the case of Sebastian Bloch reminds him of Greek tragedies. The secret service director confesses that he is actually a fairly erudite man. Notably he is reminded of the "play about Oedipus" (p. 442). And for him this similarity raises the question what (in the case of Bloch) the "twist", the "weakness" ( $\dot{\alpha} \mu \alpha \rho \tau i \alpha)$ is, as Aristotle (1982) phrased it. According to Gregg, it is his overestimation of intelligence: "One man's intelligence. There's something else that's much more important. But he doesn't know it" (p. 442). In other words, psychoanalytically speaking, for all his intelligence as a scientific agent ( $S_{2}$ in the upper-left position), Bloch failed to acknowledge the unconscious motives that inexorably drew him towards the Thing. A drastic change of perspective, a self-analysis is required (in accordance with the discourse of the analyst) to become aware of the agency of the gadget, of the impact of the gadget, not only on society at large, but first and foremost on the scientific subject, on Bloch's own existence, luring him into a liaison the structure of which is captured by the matheme of desire $(\$ \diamond a)$.

In order to realise his goal, Sebastian stops being a scientist and becomes a manager, a politician, and eventually he becomes a visionary, a sage $\left(S_{2} \rightarrow S_{1}\right)$ who envisions the pattern, the whole, as in the Lacanian quadruped reflecting the discourse of the analyst. The position of the scientist is suspended ( $S_{2}$ pushed back into the lower-left position). His involvement with the gadget requires a rupture with his scientific past, a conversion. The interaction with and exposure to the gadget changes

\footnotetext{
${ }^{14}$ Another explanation is that Picasso, while working on the mural, noticed the Russian Sputnik orbiting overhead (at Nice Airport), an experience which filled him with excitement (Di Lauro 2004).
} 
him dramatically ( $\$$ in the upper-right position). "There were two men in Sebastian Bloch", but only one of them was the scientist (p. 158). The confrontation with the gadget reveals (and intensifies) this split, this Spaltung. First of all, it results in various kinds of symptoms, turning Sebastian into a chain-smoking anorectic with an uncanny stare ( $\$$ in the upper-right position), someone who is willing to betray his past, up to the point of producing damaging fabrications, only to secure (temporarily at least) his continued interactions with the Bolt. For although the Bolt poisons science; Bloch "needed the Monster" to survive (p. 377). But eventually, he identifies himself with the position of the sage who sees the pattern, sees farther and clearer than others, a kind of invisible, intangible guiding Spirit $\left(\mathrm{S}_{1}\right.$ in the lowerright position), someone who finally manages to become "completely detached" (p. 414). While attending countless conferences, and reading and co-authoring endless documents, he is "no longer present". His mind functions swiftly and accurately, but he himself is absent, in another realm, his own realm, which claims him more and more, hoping to achieve a metamorphosis, a transcendence of "fleshy reality" (p. 415).

\subsection{Aftermath: Science and Art}

Chevalier's novel is not the final word on the case history of Oppenheimer. In his opera Dr. Atomic, composer John Adams creates a quantum physics soundscape (with its stochastic, aleatory, random music) to reveal how Oppenheimer, exposed to the blinking gadget, falls victim to the matheme of desire. Robert Wilson, a close collaborator of Oppenheimer on the Manhattan Project, later became the first director of Fermilab (near Chicago), the second largest scientific contrivance in the world (next to CERN). In this capacity, he was actively involved in the architectural design of the research facility. He wanted the Fermilab to look like a cathedral, not only because the size of the nucleus compares to the atom like a fly inside a cathedral, but notably because, for Wilson, scientific facilities such as particle colliders are the cathedrals of the present. Science, he argues, has no practical purpose (Hilts 1982). It manufactures nothing, makes no profit. Its function is primarily spiritual. It is purely concerned with the ultimate nature of matter. There are no practical applications, no more than for literature, theatre, poetry, or painting. Scientific understanding has its inherent cultural value. It has great beauty. Once, asked whether his expensive accelerator would in any way further the country's security, he decidedly denied it. It has nothing to do with defending our country, he argued, except for making it worth defending. Psychoanalytically speaking, the particle collider, exemplifying the return of purified, cleansed science, is Wilson's effort at reparation (Wiedergutmachung). 

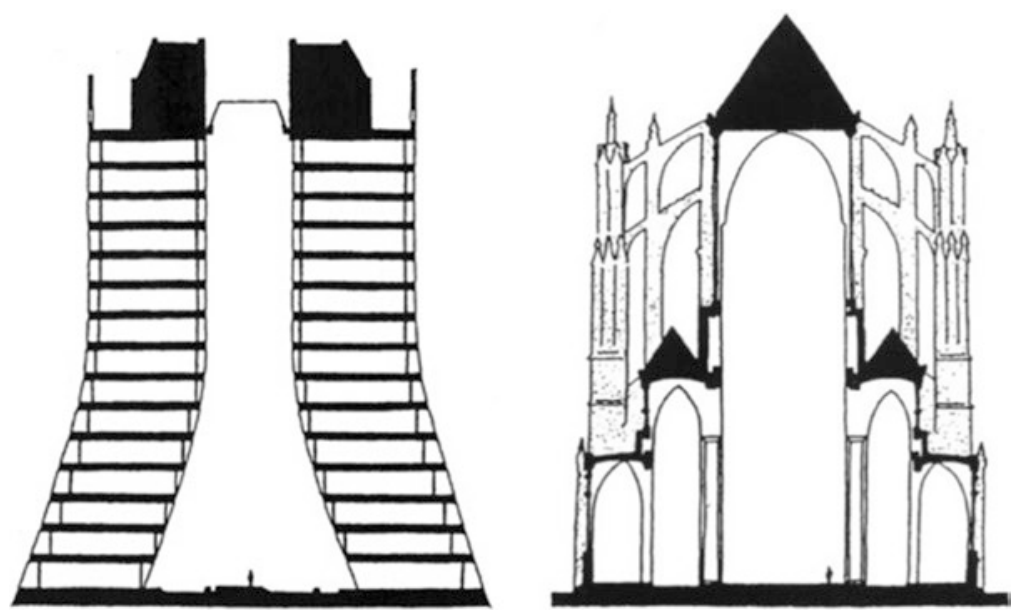

As to pure science, the novel The Search (discussed above) contains an interesting dialogue between the protagonist and his girl-friend (presented in the novel as a "disturbance" to his work), who tells him about a novel she had read: "I was Reading Arrowsmith the other day" (Snow 1959, p. 59), a novel about practical science, medical science. And now she wonders why the protagonist immerses himself in basic research, instead of going for "the Arrowsmith kind" of science (p. 59), with its practical benefits for society at large. The answer basically is that the protagonist wants to keep his science "pure". But if pure science already becomes entangled in tragic integrity challenges, what about "the Arrowsmith kind"?

Open Access This chapter is licensed under the terms of the Creative Commons Attribution 4.0 International License (http://creativecommons.org/licenses/by/4.0/), which permits use, sharing, adaptation, distribution and reproduction in any medium or format, as long as you give appropriate credit to the original author(s) and the source, provide a link to the Creative Commons license and indicate if changes were made.

The images or other third party material in this chapter are included in the chapter's Creative Commons license, unless indicated otherwise in a credit line to the material. If material is not included in the chapter's Creative Commons license and your intended use is not permitted by statutory regulation or exceeds the permitted use, you will need to obtain permission directly from the copyright holder.

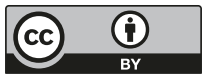

